\title{
RECONCEPTUALIZACIÓN DE LA IDENTIDAD PERSONAL Y EDUCACIÓN PARA LA AUTODETERMINACIÓN POSIBLE
}

\author{
The reconceptualisation of personal identity and \\ education for possible self-determination
}

\section{Reconceptualisation de l'identité personnelle et éducation pour l'autodétermination possible}

\section{Antonio BERnAL GuERRERO}

Universidad de Sevilla. Facultad de Ciencias de la Educación. Departamento de Teoría e Historia de la Educación y Pedagogía Social. C/ Camilo José Cela, s/ $n$. 41018 Sevilla. Correo-e: abernal@us.es

Fecha de recepción: enero de 2005

Fecha de aceptación definitiva: abril de 2005

BIBLID [(1130-3743) 17, 2005, 97-128]

\section{RESUMEN}

En este artículo, procurando superar las tensiones dialécticas entre las ideas modernas y posmodernas, se analiza la identidad como construcción de significado en interacción y desde la narrativa personal. En este sentido, enfatizamos, dentro de la condición esencialmente dinámica de la identidad, su carácter proyectivo como "personalidad escogida". La identidad personal es una parte de la personalidad, esa parte que podemos imaginar, inventar, crear y escoger, con nuestras posibilidades y limitaciones individuales y situacionales, por nosotros mismos. Nuestra capacidad de elegir, de decidir, es ciertamente limitada. No obstante, en este ámbito se define la libertad humana, la cual concebimos aquí como nuestra capacidad de autodeterminación posible. Consecuentemente, refiriéndonos al propio sujeto, delimitamos los principales dominios formativos para la autodeterminación posible, desde la que cabe desplegar el descubrimiento de las estrategias educativas pertinentes para la construcción autónoma de la identidad. 
Palabras clave: identidad personal, identidad narrativa, personalidad, sujeto, libertad, autodeterminación, construcción de la identidad, dominios formativos de identidad personal, Teoría de la Educación.

SUMMARY

While attempting to overcome the dialectic tensions existing between modern and post-modern ideas, this article analyses identity as the construction of meaning in interaction and from the personal narrative. In this regard, we stress, within the essentially dynamic condition of personality, its projective character as the "chosen personality". Personal identity is one part of personality; this is the part that we ourselves, within our individual and situational possibilities and limitations, can imagine, invent, create and choose. Our capacity to choose, to decide is evidently limited yet within this restricted ambit human liberty, something that we regard here as being our possible capacity for self-determination, is defined. As a result, and referring to the subject him or herself, we define the principle formative ambits for this possible self-determination and thence proceed to discover the educational strategies relevant to the autonomous construction of the identity.

Key words: personal identity, narrative identity, personality, subject, freedom, self-determination, identity construction, formative ambits of personal identity, Theory of Education.

SOMMAIRE

Dans cet article, en essayant de dépasser les tensions dialectiques entre les idées modernes et postmodernes, est analysée l'identité comme construction de signifié en interaction et depuis la narration personnelle. Dans ce sens, nous insistons, dans la condition essentiellement dynamique de l'identité, sur son caractère projectif comme "personnalité choisie". L'identité personnelle est une partie de la personnalité, cette partie que nous pouvons imaginer, inventer, créer et choisir, avec nos possibilités et limitations individuelles et situationnelles, pour nous-mêmes. Notre capacité de choix, de décision, est certes limitée. Cependant, dans ce cadre se définit la liberté de l'homme, que nous concevons ici comme notre capacité d'autodétermination possible. En conséquence, en nous rapportant au propre sujet, nous délimitons les principaux cadres formateurs pour l'autodétermination possible, depuis laquelle il y a lieu de déployer la découverte des stratégies éducatives pertinentes pour la construction autonome de l'identité.

Mots clef: identité personnelle, identité narrative, personnalité, sujet, liberté, autodétermination, construction de l'identité, cadres formateurs de l'identité personnelle, Théorie de l'Éducation. 
Formular propuestas pedagógicas para la construcción de la identidad requiere previamente llegar a comprender en qué consiste la identidad y su compleja configuración. Ni sólidamente reflejada en una identidad sustancial, ni tampoco definitivamente perdida en múltiples identidades sucesivas, la construcción de la identidad parece desarrollarse en una dinámica espacio-temporal en la que quedan contenidos el flujo y la estática de la conducta humana. No parece imposible que los sujetos puedan reconocerse en unos determinados relatos identitarios, en unos significantes y significados concretos. Subrayando el carácter narrativo de la identidad personal, así como su construcción en interacción, procuramos mostrar el sentido de la identidad en relación con el concepto de personalidad. Posteriormente, acometemos la nada fácil tarea de tratar de definir algunos dominios formativos en el sistema del sujeto, vinculados a la configuración de su identidad. El debate permanece abierto.

\section{REPENSAR LA IDENTIDAD}

Desde distintos enfoques, a lo largo del siglo XX, la idea moderna de identidad ha sido enérgicamente criticada. Ya sea en el ámbito de las ciencias sociales, ya sea en el campo de la filosofía, los fundamentos de la moderna concepción del sujeto han sido cuestionados gravemente. Los pensadores de la "Sospecha" (eminentemente Marx, Nietzsche, Freud) vinieron a significar un despojo para la autoconciencia y el antropocentrismo renacentista y moderno. Ni el Sol gira a nuestro alrededor, ni pertenecemos a otra cepa que el resto del mundo animal. Ha sido tal el aluvión de críticas que, hoy, cualquier discurso que incluya al sujeto precisa en primer lugar legitimación, puesto que, como ya sabemos, incluso se ha preconizado la muerte del sujeto, de la idea de sujeto, la cual parecería haber corrido paralela suerte al paradigma de la modernidad. Los potenciales interpretativos de la modernidad, puestos de manifiesto en los "grandes relatos" históricos y filosóficos, cuyo servicio llegaba hasta la propia interpretación y autoanálisis, se habrían agotado con la propia modernidad, progresiva y crecientemente incapaz de poder llegar a una interpretación de sí misma que pudiera dar sentido a la propia evolución cultural de los tiempos modernos.

Con los diversos estructuralismos, como es conocido, se alcanzó la culminación de todas las críticas del yo unitario y autosustante de la modernidad ${ }^{1}$. La cuestión del sujeto quedaba al margen. No se trata de reconstruir o de descubrir el sujeto, como afirmaba la filosofía clásica moderna, sino simplemente es preciso diluirlo. Nos diría Lévi-Strauss (1968) que el fin de las ciencias del hombre no es

1. Aunque pueden señalarse muchos tipos de estructuralismos (matemático, lógico, psicológico, lingüístico, sociológico), en lo referente a la cuestión de la identidad, en este punto, nos parecen particularmente reseñables el estructuralismo antropológico (LÉVI-STRAUSS, 1968), el estructuralismo literario (BARTHES, 1974) y el estructuralismo filosófico (LACAN, 1970; Althusser, 1967; FouCAult, 1970, Derrida, 1984). 
constituirlo, sino disolverlo. El estructuralismo marxista incide en la disolución y descomposición del sujeto activo de la historia, tradicional en sus análisis, para acabar propugnando su dilución en el impersonal y objetivo ámbito de las relaciones sociales. Así, nos propuso Althusser (1967) la imposibilidad de llegar a conocer algo sobre los hombres si no derribamos el mito filosófico del hombre. Conforme a la idea de la primacía del orden simbólico y de los códigos, Lacan (1970) sostuvo la única existencia de estructuras inconscientes independientes de los sujetos. No era objeto del psicoanálisis, según Lacan, de acuerdo a su concepción estructuralista, el hombre, sino que más bien su finalidad será reconocer en la ciencia un rechazo del sujeto. La crisis de la idea clásica moderna de identidad personal, el conocimiento de la fragilidad de la naturaleza de la subjetividad, se ha producido en un marco social, cultural e histórico progresivamente dominado por la "máquina burocrática ${ }^{2}$, por la creciente subyugación colectiva a los dictados racionales y normativos y, en fin, por una alta y creciente complejidad de los diversos modos de organización imperantes en la economía y en el Estado.

Para la crítica posmoderna, la noción moderna clásica de identidad no es sino una ilusión, una fantasía, una ensoñación. Desde mediados del siglo XX, mediante el desarrollo de la interacción humana con las tecnologías de la información, en Occidente se fue desarrollando una nueva modalidad de construcción del sentido del si mismo. Este cambio se puso de manifiesto en el aumento de las presiones externas al individuo para que éste acabe acomodando su propio sentir y actuar a la experiencia del otro. En realidad, este nuevo escenario de interacciones humanas lo que hace es enfatizar la multiplicidad del sí mismo. Las nuevas tecnologías de la comunicación han agilizado las relaciones interpersonales, pero también han ampliado los márgenes de las relaciones a sociedades visibles y a comunidades virtuales. Las identidades cambian con el cambio de dominios de relación. Sin certezas absolutas, el individuo posmoderno vive un incesante tráfago de ideas del que se desprende al menos alguna certidumbre: no hay una sola forma de humanidad verdadera. Las múltiples racionalidades específicas que requieren al sujeto le condenan a la fragmentación, a su radical desmembramiento, a su disolución ${ }^{3}$. Con la posmodernidad, se ha pasado del moderno reconocimiento del sujeto, de su identidad constitutiva, a su cuestionamiento radical, como han puesto de manifiesto las

2. Recuérdese la metáfora empleada por los teóricos críticos: "mundo de la Administración Total".

3. Planteando la tesis de que el ultrahombre nietzscheano no resulta interpretable como un sujeto reconciliado dialécticamente, sino escindido y disperso, y no sólo de forma provisional, lo cual enfatiza la noción central de "crepúsculo del sujeto", Gianni VatTimo nos dice en El sujeto y la máscara (2003, 160): "El ego es una imagen históricamente condicionada, de modo que la persecución de fines egoístas no es jamás un dato "último" de la acción, sino que, por el contrario, indica la radical pertenencia de la misma a la época, a la sociedad, al grupo particular en que se vive y con el que nos enfrentamos". La "VOZ de la conciencia", cuya presencia en nosotros nos impulsa al cumplimiento de determinadas acciones "morales", no es más que la presencia en nosotros de la autoridad de la comunidad en que vivimos; no hay moral donde no existe voz de la conciencia, o sea, donde no hay sociedad. 
filosofías de la diferencia, llegando al deconstruccionismo (Ávila, 1999), esto es, a la negación de su posibilidad unificadora. Los pensadores posmodernos terminan por eliminar cada raíz experiencial en un sentido de continuidad personal. La proclamada disolución del sujeto se explica por la separación entre el significado y la experiencia. El significado no se refiere a quien desarrolla la experiencia, sino que se define por la diferencia con otros significados, dentro de un sistema lingüístico cerrado. Dentro de este sistema, el significado desaparece en una multiplicidad de referencias, diluyéndose en una multiplicidad de relaciones de diferencia y de oposición con otros significados constituyentes del sistema. Al no haber nada fuera del texto, nos dice Derrida, la preponderancia del lenguaje sobre la experiencia conduce a la idea de un sí mismo proteico y aglutinado permanentemente a las múltiples formas discursivas que componen el universo lingüístico, pre-existente al propio individuo. Así, la palabra del sujeto es privada de intencionalidad. Como ha escrito Gergen (1997, 110): "si el lenguaje no contara con los pronombres "yo" y "tú", tal vez no podría reconocerse a las personas como dotadas de un ser individual". Al carecer de la intencionalidad del significado, la capacidad requerida del individuo posmoderno es la de darse sentido según aquellos dominios discursivos en los que interviene. El sí mismo, para los posmodernos, varía en función de la participación discontinua en múltiples dominios de discurso, lo cual puede elevar el grado de exigencia comportamental para el sujeto hasta límites verdaderamente asfixiantes, puesto que mantener cierto nivel deseable de autoestima en un contexto sometido a la saturación social obligará al individuo a desempeñarse eficazmente en múltiples aspectos: como profesional, como amigo, como hijo, como padre, como miembro de una pareja, como persona culta, como conocedor de la política, como sujeto que disfruta del ocio, como individuo capaz de gestionar bien el dinero... Esta disgregación del sujeto en una multiplicidad de roles, esta multiplicación del sí mismo, bien podría quedar reflejada en la denominada "multifrenia", a la que se ha referido Gergen (1994). Los posmodernos afirman que, en realidad, lo que hay es un proceso multiplicador del sí mismo, no un sí mismo independiente y unitario. De este modo, la identidad va cambiando la imagen de sí mismo, a la par que va esbarándose entre cientos de campos de interacción.

Ante las fuertes críticas que ha recibido la concepción moderna de la identidad, el sueño de un sujeto fuerte, subsistente a toda contingencia, parece desplomarse, aunque encontremos eminentes voces aún defensoras de las raíces del orden moderno, como la de Charles Taylor ${ }^{4}$, si bien desde posiciones ciertamente

4. En su extensa investigación sobre las fuentes de la identidad moderna, el filósofo quebequés y canadiense Charles TAYLOR (1996), cuya obra está dedicada en gran parte a narrar el origen de lo que podemos llamar la identidad moderna y centrada en el problema de la constitución del sujeto moral, plantea que la contemporánea tendencia hacia la interioridad no constituye desastre alguno, sino que más bien es el resultado de los múltiples esfuerzos realizados por el hombre acerca de la definición y alcance del bien, el producto de lo que él mismo denomina la afirmación de la vida corriente. En este sentido, ha propuesto una ética de la autenticidad, caracterizada por centrarse en el concepto de bien 
críticas sobre los peligros de la propia modernidad (auge del individualismo, dominio de la razón instrumental y despotismo del sistema en detrimento de la libertad individual y colectiva). El sujeto crítico y reflexivo, considerado como ya dado, no parece ser más que una entrañable ilusión. Por lo demás, ya los clásicos teóricos frankfurtianos ${ }^{5}$ denunciaron la tendencia de la sociedad de masas a crear una identidad totalitaria, como asimismo Weber $^{6}$ había alertado al mundo contemporáneo

y no en el de justicia. Taylor critica las éticas inspiradas en la noción de justicia, aquellas éticas de tipo procedimentalista, racionalista, a las que considera un resultado no deseable del proyecto moderno. La identidad del yo está en parte definida por la identidad de la comunidad, por ello Taylor -incluido entre los autores de la llamada corriente comunitarista - ha insistido en la importancia de reconocer la identidad de la comunidad, de forma análoga a como debe ser reconocida la del individuo. Subraya Taylor que la identidad personal se define por los compromisos e identificaciones que proporciona el contexto dentro del cual el sujeto procura determinar lo valioso, que delimita el horizonte dentro del que él ha de adoptar posiciones concretas. El yo sólo existe, añade Taylor, dentro de la denominada «urdimbre de interlocución", es decir, no hay identidad personal solamente por tener una posición respecto de los asuntos morales, sino por incluir una referencia a una comunidad definidora. De manera consecuente, Taylor ha propugnado una política del reconocimiento de las diferentes identidades -el propio Taylor milita en el Movimiento Nacionalista de Quebec-, capaz de alcanzar un equilibrio entre la legítima demanda de igualdad y dignidad democrática y la atención a las peculiaridades de las distintas tradiciones culturales. El enfoque de Taylor, en fin, se funda en que toda concepción adecuada del yo y de su unidad narrativa, de la moralidad y de la racionalidad práctica ha de reconocer la importancia fundacional de unos marcos sustantivos de valoración, y esos marcos son esencialmente comunitarios en su naturaleza.

5. Los teóricos críticos frankfurtianos (Adorno, Horkheimer) denunciaron la cosificación moderna de la subjetividad. En una sociedad bajo el dominio de la "razón instrumental", que impulsa la uniformidad absolutizándola, que propala una identidad totalitaria que anula todo conato de auténtica autonomía individual, la subjetividad genuina se difumina. En la Teoría Crítica hay un rechazo del sujeto, pero del sujeto metafísico, de la visiôn esencialista del sujeto, así como igualmente se rebela contra la despersonalización de los individuos que genera la cultura de masas; pero los pensadores de la escuela de Frankfurt no pretendieron consumar la aniquilación del sujeto. Ante la falta de transparencia de las relaciones sociales y del entramado de mediaciones institucionales y discursivas en las que actúan las fuerzas que terminan configurando a los sujetos, la Teoría Crítica propone como proyecto un sujeto libre, crítico y reflexivo. Concienciados de la inercia política, los teóricos críticos no consideran las posibilidades de las libertades individuales al margen de la historia material de la sociedad. La teoria critica propugna la condición intersubjetiva de la identidad del individuo, pero al tiempo reconoce en la autonomía auténtica del individuo - gracias a una razón comunicativamente fundada- la potencialidad contributiva a la vitalidad política y social de la colectividad. La propuesta descosificadora de los teóricos críticos asume la contingencia permanente de la subjetividad y su carácter de supraindividualidad. No es posible representarse la espontaneidad subjetiva, reflexionante, al margen de la sociedad, apartada de la omnipotencia de los contextos sociales.

6. Max Weber, uno de los autores más influyentes en el pensamiento sociológico y filosóficosocial contemporáneo y particularmente en los pensadores de la Escuela de Frankfurt, denunció que, paralelamente a los fenómenos de racionalización social y cultural en Occidente, se ha ido menoscabando la libertad. La condición histórica misma de posibilidąd del individualismo moderno, paradójicamente, ha ido acompañada de procesos que han mermado la libertad del individuo: el disciplinamiento vital, la represión de los instintos vitales, la reducción o supresión de la espontaneidad, el auge del capitalismo tras los movimientos renacentista y reformista y la práctica calvinista de un determinado ascetismo que gira alrededor del productivismo. Aquella proverbial metáfora de Weber, la 
sobre la progresiva pérdida de libertad en el seno de la sociedad moderna occidental, engendradora de una peligrosa cultura cosificadora del sujeto. Si admitimos que lo pueda tener, un sujeto fuerte, reflexivo y crítico, genuino, únicamente parece tener ya sentido como proyecto. En cualquier caso, esta idea de sujeto distará mucho de la noción de sujeto autosustante y unitario proclamada, con diversas matizaciones, por los clásicos modernos o premodernos.

Queda, pues, en cuestión la concepción moderna del yo como un sujeto autocontenido a la busca de una identidad auténtica por descubrir, con libertad total de actuación y de transformación de la realidad. Precisamos una nueva manera de pensar, o mejor de repensar, la identidad. Tanto la crítica epistemológica al sujeto esencial como la proclamada disolución de la identidad en la posmodernidad, han terminado por negar la posibilidad de una construcción con sentido de la identidad de la persona. A pesar de todo, el sujeto retorna, la idea de sujeto vuelve a emerger con fuerza (Sanfélix, 1997). Hoy, reivindican su individualidad todos los distintos y todas las diferentes de todo tipo, y aun con animoso orgullo. Estas exigencias de reconocimiento también tienen lugar en el nivel de las colectividades, donde las demandas de autodeterminación no cesan. Seguramente nunca como ahora habíamos asistido a una reivindicación tan vigorosa de la autonomía, a una solicitud tan firme del reconocimiento de lo individual y de lo distinto. Cuanto más compleja se ha tornado la sociedad, cuanto más difícil es desvelar los entramados sociales en los que hemos de desenvolvernos, cuanto mayor es la intransparencia del porvenir, cuanto más sumidos estamos en la "sociedad invisible" (Innerarity, 2004), más acuciante parece la necesidad de revelar y de revelarnos, de proclamar y mantener nuestra identidad personal, de decirnos y decir "existo", "existimos", "soy yo", "Somos nosotros", sujetos únicos, diferentes, irrepetibles, humanamente contingentes y genuinamente distintos.

Al margen del modo y contenido de las respuestas que se den a la pregunta por la identidad, ciertamente la preocupación por los procesos de identidad es muy actual. Una exigencia prioritaria se nos impone: repensar la cuestión de la identidad. Pero la discusión sobre la identidad no parte de cero, ya no se puede ignorar todo el saber acumulado sobre sus determinaciones y condicionamientos. El sujeto fuerte de la modernidad difícilmente puede sostenerse hoy, después de tantas contribuciones críticas que han puesto de manifiesto la fragilidad del sujeto y aun su levedad. Una apretada síntesis de las muchas críticas realizadas parece indicar que el sujeto, más que instancia sustancial y dotada de una identidad sin quiebra, es ámbito para la experimentación y la diferencia, desde las que únicamente cabe construir de alguna manera la propia identidad; antes que fundamento absoluto de todo conocimiento y acción, la identidad más bien es punto de llegada.

\footnotetext{
"jaula de hierro", nos contextualiza palmariamente la nueva situación de los individuos: presuntamente libres, con capacidad de autodeterminación, se encuentran, contradictoriamente, gravemente mermados o aniquilados, reducidos a la pasividad y a la vida gregaria, alejados de una autonomía real y distanciados de todo desarrollo que les permita determinar sus propias condiciones y formas de vida.
} 


\subsection{El sujeto como constructor de significado. La identidad construida en la interacción y desde la narrativa}

A través de la manera de delinear la identidad en el tiempo, podemos reconocer la dialéctica entre el concepto moderno y el posmoderno de identidad. Una idea del sí mismo como algo permanente, inalterado en el transcurso de la vida, frente a otra idea que refleja un conjunto de sí mismos múltiples y cambiantes con las situaciones que va viviendo el individuo. Todos tenemos la experiencia de discontinuidad, pero también poseemos cierto sentido de permanencia. He aquí una aporía cuya superación nos parece clave para la comprensión del sujeto, para la comprensión de la condición humana, para la elaboración de una teoría de la acción del ser humano y, en definitiva, para una construcción más plausible de la teoría de la educación. Si registráramos la conducta de una persona en su vida cotidiana nos apercibiríamos en seguida de que su personalidad no es algo fijo, estático, sino que, conservando ciertos patrones estables de comportamiento, más bien consiste en una suerte de variaciones para adaptarse a los cambios en las necesidades y en las circunstancias diversas. En realidad, somos muy variables. Visto así, la conducta del sujeto parece ser un fenómeno adaptativo capaz de atender a las múltiples exigencias situacionales que requieren flexibilidad y respuestas diferentes. Efectivamente, la conducta humana puede considerarse un fenómeno de adaptación, en el más amplio sentido del término; pero esta capacidad adaptativa no sólo se relaciona con lo cambiante, sino que también se asocia al mantenimiento de cierto sentido de continuidad en el espacio y en el tiempo, cierta coherencia en el sentido de estabilidad comportamental.

Decía Husserl (2002) que la temporalidad estructura la experiencia vital. Afirmaba el eminente fundador de la fenomenología que el presente de nuestra existencia no es un mero punto en la linealidad temporal, es un acontecer en el que se integra lo que ha sido con la anticipación de lo que será. Pero a esa dimensión existencial, delimitada por la estructura temporal de la experiencia de la vida, en realidad, únicamente puede accederse mediante la cultura, a través de los símbolos, los discursos, los textos, las narraciones ${ }^{7}$. Como expone Savater $(2004,57)$,

7. La narratividad cumple un papel esencial en la configuración de la identidad personal y aun en la constitución de la historia colectiva. A esta nueva conciencia acerca de la función central de la narración en la vida humana, por cierto, han contribuido múltiples disciplinas en los últimos lustros: sociología, antropología, historiografía, psicología, teoría literaria y hermenéutica filosófica. La concepción actual de la narrativa en las ciencias humanas, sociales, tiene una ascendencia clara en el denominado "giro lingüístico" (RORTY, 1979), es decir, en la asunción de determinadas ideas provenientes de la filosofía contemporánea, en gran medida procedentes del enfoque hermenéutico (HEIDEGGER, 2003; GADAMER, 2002; RICOEUR, 1996). La perspectiva narrativa viene a decirnos, sintéticamente, que toda la significación de la experiencia del sujeto está moldeada por los significados estructurados en el lenguaje que se ha ido desarrollando históricamente en un determinado contexto sociocultural. De este modo, la forma humana que tenemos de conocer el mundo está determinada por encontrarnos siempre dentro de un marco histórico y social que condiciona toda comprensión de la realidad. De alguna manera, 
"Somos animales forzosamente simbólicos", y por eso hay una estrecha relación entre el discurrir de la experiencia y el dominio lingüístico. La temporalidad de sí mismo solamente puede articularse mediante el lenguaje. Si el ámbito lingüístico puede reordenar la experiencia del vivir es justamente porque a ella se refiere de continuo $^{8}$. El sujeto, en suma, accede significativamente a la propia experiencia a través del uso de símbolos, de determinados códigos o sistemas simbólicos, que hacen posible la interpretación ${ }^{9}$. Al mismo tiempo, la estructura temporal de la experiencia se halla unida a la reconfiguración simbólica. La temporalidad de la experiencia se puede entender cuando los acontecimientos de la vida se entrelazan en una trama de significados.

Una trama de significados es tanto como la organización de los acontecimientos en una historia. La construcción de la historia se halla íntimamente vinculada a la constitución de su personaje, es decir, del quién al que se refieren las acciones y también las pasiones que configuran la narración. La identidad deambulante entre los diferentes juegos lingüísticos y diversas narrativas, entre las múltiples modalidades discursivas, parece ir acompañada de un quién del discurso que, en las incontables situaciones, de algún modo permanece presente a sí mismo. Se trata de un quién que, entre tanto se accede a la heterogeneidad de la experiencia, representa un modo de continuidad de sí mismo (Shrag, 1997). El sentido de unidad de la historia se corresponde con el sentido de continuidad personal y la variabilidad de los acontecimientos se corresponde con las múltiples situaciones de la vida. La identidad de sí mismo se debate entre la continuidad y la variabilidad. Mediante la construcción narrativa, reconfiguramos la experiencia tratando de

puede decirse que el lenguaje hace al mundo y al sujeto, puesto que la sociedad está estructurada lingüísticamente, en un cúmulo de significados (BERGER y LUCKMANN, 1967). Como la realidad y el sujeto se ordenan y estructuran en el lenguaje, el modo en que los sujetos pueden dar sentido a su experiencia, la manera en que pueden dotarla de significado, es precisamente en el seno de estas formas discursivas. La estructuración, la reestructuración de la experiencia la realizamos mediante una trama narrativa. La estructuración narrativa de la experiencia humana deviene en la construcción de una identidad narrativa, representada como una trama histórica en continua expansión a través de la existencia del sujeto. Frente a los postulados del positivismo lógico y de la metafisica moderna, propugnamos, desde una perspectiva hermenéutica, la relevancia innegable que la narración juega en los modos en que los seres humanos construyen su memoria, su presente y su futuro (COLOM y MÈlıch, 2003).

8. Esta integración entre lenguaje y experiencia del vivir, el nacimiento de la comunicación lingüística, allá en la noche de los tiempos, es la que dio origen al Homo sapiens sapiens. El hecho de poder reconfigurar la experiencia en determinadas estructuras de sentido comunicable favoreció, sin duda, las posibilidades de supervivencia de la especie, al facilitar la coordinación de las prístinas comunidades para valorar y defenderse de los peligros amenazantes y para explotar más eficazmente los recursos disponibles.

9. Refiriéndose al carácter de animales simbólicos que somos, SAVATER asocia la moralidad a la capacidad de soportar la vida como antesala de la muerte, porque los demás animales no son mortales, no tienen conciencia de la muerte, mueren pero no son mortales. "Mortales somos sólo los que sabemos que vamos a morir y los que vivimos pendientes del tiempo. Y es el tiempo, precisamente, el que muchas veces nos hace actuar mal, porque si tuviéramos todo el tiempo del mundo, probablemente todos seríamos buenos" $(2004,54)$. 
conformar nuestra identidad. La estructura temporal de la experiencia parece adquirir forma, pues, en un dinamismo continuo, en la construcción de la identidad del quién, del personaje, y de la historia, que de alguna manera permanece en el incesante discurrir de la vida. A este respecto es ya célebre la definición de «identidad narrativa" que nos ofrece Paul Ricoeur, puesto que, con el genial filósofo hermenéutico, pensamos que la identidad personal "sólo puede articularse en la dimensión temporal de la existencia humana" $(1996,107)$, y es precisamente la identidad narrativa el género de identidad que la composición narrativa puede crear, mediante su dinamismo. Dado que todo relato suscita cuestiones éticas, para Ricoeur, la narrativa sirve de propedéutica para la ética. Asimismo con una preocupación primordialmente ética, desde otro enfoque, Alasdair MacIntyre (1987), destacado representante contemporáneo del comunitarismo, recuperando en cierto modo la herencia aristotélica, también ha insistido en el orden narrativo de la vida humana ${ }^{10}$.

Desde la psicología cultural, Bruner (1991) ha proclamado la existencia de un "yo distribuido", a modo de un engranaje de participaciones, resultado de las múltiples situaciones en las que participa el individuo. El sujeto construye su identidad como individuo diferenciado de otros individuos. Pero, al mismo tiempo, el yo adquiere significado en las circunstancias históricas de la cultura en la que se inserta y desenvuelve. El yo se sostiene en unos significados, lenguajes y narraciones

10. Según MacINTYRe, el ser humano es esencialmente un animal que cuenta historias, y que en ciertos casos puede ser un contador de historias que aspira a la verdad. El orden narrativo de una vida humana única se debe a que el sujeto posee unidad narrativa. La estructura narrativa de la vida humana se halla marcada por dos aspectos fundamentales: de un lado, por la teleología, pues vivimos mirando a un futuro probable; $y$, de otra parte, por la impredecibilidad, puesto que esa imagen de futuro no garantiza qué sucederá en cada circunstancia y en cada acción. La unidad de una vida individual es la unidad de la narraciốn encarnada por una vida singular, una vida que posee la unidad y la continuidad de una búsqueda cuyo fin es el hallazgo de la verdad sobre esa vida y lo que es bueno para ella. Esa unidad de la vida como un todo sobre la que cada hombre indaga es la unidad de una narración dramática, de una historia cuyo resultado puede ser un éxito o un fracaso para cada sujeto concreto. Como cada individuo es parte inseparable de la comunidad en la que acontece su narración y su vida, sostiene MacIntyre que no puede haber un antagonismo sustancial y duradero entre lo que constituye su bien y el bien de la comunidad. El individuo se identifica a sí mismo y es también identificado por los demás a través de su pertenencia a una multiplicidad de grupos sociales. En este sentido, ser tema de la narración que se desarrolla desde nuestro nacimiento hasta nuestra muerte deviene en reconocerse responsable de las acciones y experiencias que configuran esa vida narrable. A lo largo de su existencia, el sujeto es coautor de su propia historia y su vida alcanza sentido en la medida en que ésta es inteligible, lo cual sólo es posible si el sujeto conoce con claridad qué persigue. La meta del hombre no viene situada únicamente en relación a las prácticas, sino además con la vida buena, que es "vida dedicada a buscar la vida buena para el hombre" (1987, 271). Las virtudes que se necesitan para su búsqueda son precisamente, nos dice el filósofo escocés, aquellas que nos capacitan para alcanzar a entender más y mejor en qué consiste la vida buena. La perspectiva comunitarista se basa en que los seres humanos son "animales auto-interpretativos", cuya identidad como sujetos depende de su orientación y relación con las ideas del bien, que proceden de su comunidad lingüística. De este modo, MacIntyre ha conjugado narrativa y racionalidad práctica. 
históricamente determinados. No se trata de algo que proceda de las oscuridades y profundidades del ser. La identidad se construye mediante procesos de diferenciación personal, de singularización ${ }^{11}$; pero también se construye en relación dialéctica con el otro, con los otros, en contextos culturales determinados. El "yo distribuido" puede considerarse un "suceso verbalizado", una especie de metasuceso que da coherencia y continuidad a la experiencia del individuo. Aquí es donde se incardina el carácter narrativo de la identidad personal. No es meramente el lenguaje por sí mismo, sino la narrativa lo que está en la base de la identidad personal; en este sentido, habla Bruner de self-making-narratives, narrativas que permiten la construcción de la identidad. Estas narrativas implican un equilibrio entre autonomía personal y compromiso con los demás. El yo no es una sustancia que mana de las honduras de la subjetividad humana, sino que, en clave bruneriana, hay que considerarlo como un diálogo entre el individuo y sus otros de referencia, para acabar siendo producto de una fabricación narrativa, de nuestro propio contar. Sin nuestra capacidad narrativa, nuestra capacidad de construir historias sobre nosotros mismos, ni siquiera nos plantearíamos la cuestión del "sentido del yo".

Ahora bien, esta capacidad narrativa también es limitada. Procuramos que el relato sea consistente, pero no podrá serlo nunca completamente, siempre hay elementos contradictorios, reacios a la integración unificadora. Incluso la narración puede que no sea ni autónoma, sino producto de otros guiones pautados, de relatos culturales que merodean al sujeto, como ha expresado Morin $(2001,180)$ : "yo hablo pero cuando hablo, ¿quién habla? ¿Acaso hablo "yo" solamente?". Tal vez nos relatamos en caleidoscopio, en combinaciones versátiles de elementos nada fijos. A veces no hay "doble vida", pero sí doble y múltiple narrativa. Podemos no contar a todos la misma historia, ni siquiera la misma que a nosotros mismos. Posiblemente, a nadie se le narra el relato completo. Como ha escrito Fierro $(2002,305)$ : "A través de una gran variedad de narraciones cada persona es capaz de construirse y de construir su mundo de modos alternativos en una increíble capacidad de multiplicarse en los argumentos narrativos y en las formas de narrar". En este sentido, algunos han señalado que no hay un relato verdadero, ni tampoco un "sí mismo" verdadero (Gergen, 1997).

Que en el sujeto hay una pluralidad de potencialidades, de personajes, parece claro; pero acaso también existe en él ese bucle recursivo porque uno es a la vez producto y productor. Por eso, el propio Morin (2001) nos indica la necesidad de reconstruir las nociones de autonomía/dependencia, de individualidad y de autoproducción ${ }^{12}$. Dentro de sus posibilidades, gracias a nuestro poder narrativo creamos y recreamos el sentido mismo de la identidad personal.

11. "Están instaladas en cada uno de nosotros o de nosotras unas ganas fuertes y aun feroces de soñar con aquel sueño que nos desveló/reveló el pintor de Figueras: "iAy, si un día pudiese llegar a ser Salvador Dalí!". Por eso Salvador Dalí puso en su DNI: "Profesión: Salvador Dalî" "(JáureguI, 2001, 324).

12. El enfoque narrativo de la experiencia humana presenta, a nuestro juicio, notables posibilidades para las ciencias del comportamiento en general, y para la pedagogía en particular. No obstante, 
Relacionada con las narrativas personales, con la identidad personal, se halla la "memoria autobiográfica", que se ha definido como la memoria para los hechos y acontecimientos de la propia vida (Conway, 1990; Conway y Pleydell-Pearce, 2000). La memoria autobiográfica es particularmente significativa para el yo, para las emociones y para la experiencia de continuidad temporal del sujeto. Los estudios recientes sobre el desarrollo de la memoria autobiográfica a lo largo del ciclo vital han mostrado una curva de desarrollo que incluye tres componentes básicos: escasez de recuerdos en los primeros años de vida ("amnesia infantil»), gran producción de recuerdos alrededor de los veinte años (reminiscence bump, pico de reminiscencia) y alta proporción de recuerdos recientes ("efecto de recencia"). Una de las razones que se dan para explicar el pico de reminiscencia es que la memoria autobiográfica cumple un papel esencial en la configuración y desarrollo de la identidad -las emociones también se vinculan a la memoria autobiográfica, en el sentido de que destacan especialmente en la construcción de los recuerdos autodefinidores-. De esta manera, en los momentos fundamentales de la constitución y consolidación de la identidad, aumentarían los recuerdos. La memoria autobiográfica parece estar estrechamente ligada al yo y, específicamente, a las "metas" del sujeto (McAdams, 2003). El conocimiento de las metas personales puede determinar la organización del conocimiento autobiográfico, así como la codificación y el acceso a dicho conocimiento autobiográfico. Como han señalado Fivush y Buckner (2003), hay una íntima relación entre las narrativas autobiográficas y el yo; pero estas narrativas no son algo estático, sino que son fluidas y dinámicas, cambiando

apreciamos algunos problemas que convendrá acometer más pronto que tarde. Parece palmario que desarrollo narrativo e identidad están íntimamente vinculados, pero sobre el conocimiento detallado de dicho vínculo aún no sabemos mucho. Habrá que indagar bastante más sobre los procesos específicos que hacen posible afirmar el carácter narrativo de la identidad. Habrá que ahondar en la pregunta sobre el significado de la experiencia humana. El flujo de esta experiencia, mejor dicho, los modos que empleamos para ordenarla, determinan lo que acaba sucediéndonos. La estática y la dinámica de esta compleja autoorganización del hombre continúan siendo un campo abierto para la investigación (GUIDANO, 1991). Tendremos que seguir interrogándonos por el origen, la vertebración y el funcionamiento de las emociones, los argumentos, las creencias, las narraciones. El estudio del desarrollo narrativo también nos conduce a la indagación de la propia estructura protonarrativa del ser humano, es decir, a tratar de conocer qué pautas secuenciales, temporales, empleamos antes de la aparición del lenguaje propiamente dicho. Por lo demás, hay el peligro de reducir el desarrollo narrativo al estricto plano social. Si la construcción del sujeto y de la realidad se produce y estructura lingüísticamente, y el lenguaje es resultado de las interacciones sociales y culturales, puede imaginarse que el individuo no es más que un producto social. Por ejemplo, puede pensarse, si nos ceñimos exclusivamente al enfoque sociocultural, que las emociones son un producto de la cultura, pero sobre la comprensión del proceso mismo relativo a las emociones seguimos sin saber demasiado. Si aceptamos que somos sistemas complejos autoorganizados, hemos de admitir también que es el propio sistema el que ordena su experiencia y su desarrollo, aunque esto se dé siempre en un contexto sociocultural. Lo cual significa que hemos de renovar la preocupación por aquellos elementos biológicos que están en la base del estricto desarrollo individual. La comprensión del ser humano está, por tanto, íntimamente vinculada a los modos en que tal sistema autoorganizado construye la interpretación del mundo en el que habita, su identidad. 
evolutiva y situacionalmente. Los procesos de identidad siempre se dan en contextos culturales determinados.

La cultura es la que permite a los sujetos ir más allá de sus predisposiciones naturales. La cultura es la que nos permite tener identidad. La educación, en este sentido, es un mecanismo fundamental. La historia humana, a última hora, tal vez no sea más que «un esfuerzo colectivo gradual por ir consolidando la tendencia a actuar mejor, de manera más completa y creativa, quizás más solidaria de lo que la naturaleza había dispuesto en un principio" (Savater, 2004, 58). Las preguntas de fondo sobre los procesos identitarios oscilan entre lo biológico y lo cultural. El núcleo de la cuestión radica en la interacción entre los poderes de las mentes individuales y los medios por los que la cultura coadyuva u obstaculiza su realización. Esto nos arroja inevitablemente a la valoración de los ajustes entre lo que una concreta cultura considera fundamental para una determinada vida buena o útil, incluyendo qué recursos dispensa la propia cultura, y de qué manera los sujetos se adaptan a tales exigencias en la medida en que han de ir afrontándolas en sus vidas $^{13}$. Puesto que, como afirma Bruner $(1996,13)$, «la educación es la principal encarnación del modo de vida de una cultura y no sólo preparación para él". Como proceso mediador de nuestra forma de responder al mundo, la evolución de la propia cultura introduce una radical "discontinuidad" entre el hombre y el resto del mundo animal. Pero aunque el mundo de la cultura ha logrado una autonomía propia, está restringido por límites biológicos y predisposiciones determinadas biológicamente. Por eso ha afirmado el propio Bruner (1996, 184): "el dilema en el estudio del hombre es entender no sólo los principios causales de su biología y evolución, sino comprender éstos a la luz de los procesos interpretativos implicados en la construcción de significado".

\subsection{La identidad personal como personalidad escogida}

Lo que habitualmente denominamos "carácter" no es una propiedad estática del sujeto, sino principio dinámico, germen de posibilidades. Entre estas posibilidades,

13. Cada cultura presenta un carácter único, pero eso no niega la posible existencia de ciertos universales en la naturaleza y la condición humanas. La exploración del rango de conductas definidas culturalmente del que es capaz nuestra especie nos puede conducir a procurar elaborar teorías que las vean como posibilidades de un repertorio humano. La cultura es variable, diversa, susceptible de adquirir unas u otras formas. Es algo que se aprende y se olvida y que nos transforma en seres muy diferentes unos de otros, con concepciones del mundo muy desiguales, con representaciones de la realidad distintas, y a menudo distantes. Ahora bien, las variaciones culturales no se oponen a la existencia de una identidad humana. Como ha manifestado el reconocido antropólogo José Antonio JÁUREGUI (2001), la sociedad primordial de los seres humanos, en tanto que somos humanos, es la antrópolis, la sociedad humana, y nuestra más fecunda cultura es la cultura humana, el patrimonio de la humanidad, entendido no como un ente monolítico y uniforme, sino como un gigantesco mosaico o puzle compuesto de un sinfín de piezas diversas y tan importantes e imprescindibles como su completa imagen final. 
la persona tiene que elegir, ha de pasar de la potencia a la realidad, de lo eventual o contingente a lo factual. Pasar de la posibilidad a la acción significa convertirse, no de modo absoluto, en autor de la propia biografía, en agente del cúmulo de actos humanos con los que tratamos de ir dando curso a los múltiples acontecimientos de nuestra existencia, eligiendo no únicamente un sistema de comportamiento, un determinado modo de actuar, sino también nuestra propia identidad. Podríamos considerar que la identidad personal es una parte de la personalidad: aquella parte que podemos escoger, elegir, que podemos decidir, con nuestras posibilidades y limitaciones individuales y situacionales, por nosotros mismos. En cierto modo, es la "personalidad elegida" (Marina, 2004). Los estudios de "personalidad", atendiendo a que en el origen de la misma se hallan elementos de orden genético y elementos de naturaleza ambiental, han incidido comúnmente en la relevancia de lo genéticamente heredado, en cuestiones de temperamento, en rasgos caracteriales de la persona, así como en lo aprendido fundamentalmente en las primeras y decisivas etapas de la vida ${ }^{14}$. Tratándose de una organización dinámica, la personalidad cambia, o puede cambiar -con la edad, con determinados acontecimientos en la vida del sujeto, con ciertas modificaciones en los roles o en algún rol importante para el individuo, etc.- (Sarbin, 1986). Así, por personalidad puede entenderse, en sentido holístico, aquello que somos, pero también aquello que podemos ser. Un adolescente se encuentra con su personalidad aprendida, anclada

14. Piénsese, por ejemplo, en la perspectiva psicoanalítica clásica, en el conductismo, en la teoría psicoanalítica del aprendizaje de Dollard y Miller, o en las teorías analítico-factoriales de los rasgos. La preocupación por las potencialidades del desarrollo mismo de la personalidad, particularmente a partir de la juventud o la adultez, vinculada a su carácter sistémico pero incompleto, abierto e inconcluso, en líneas generales, no se ha desenvuelto de modo análogo, aunque podamos encontrar ciertos desarrollos desiguales al respecto. Así, desde la perspectiva psicoanalítica-social, podemos mencionar la psicología individual de ADLER (1931), que enfatiza la importancia de la elección y el esfuerzo, y la teoria psicosocial de ERIKSON (1950), cuyo principio epigenético localiza los potenciales para el desarrollo dentro del individuo más que en su exterior. Igualmente, cabe recordar la teoría personológica de los rasgos de Gordon W. AltporT, la cual atiende a una visión esencialista de la personalidad, en la que se acaba señalando que, conforme se desarrolla la personalidad, los rasgos se vuelven "funcionalmente autónomos" de sus orígenes de desarrollo, y afirmando que "el proceso del devenir de la personalidad continúa durante toda la vida" $(1966,110)$. Tampoco puede olvidarse la notable contribución del enfoque humanista, bien representado, entre otras aportaciones, por la teoría centrada en la persona de Carl ROGERS (1951), de la cual se desprende que el crecimiento personal resulta de la emergencia de la estructura orgánica previamente ocultada, y por la teoria de la motivación bumana y la jerarquía de las necesidades de Abraham MASLOw (1962), que desemboca en la "autorrealización", donde la persona es motivada por la motivación del ser y tiene características distintivas, entre las que sobresale la creatividad. Muy posiblemente, a partir del enfoque cognitivo del aprendizaje social (Bandura, Mischel, Kelly), que reconoce múltiples potenciales sin centrarse solamente en los determinantes externos, y que admite el cambio del desarrollo porque los constructos personales pueden desarrollarse y modificarse con el tiempo, y sobre todo con la reciente aparición de las teorías psicológicas en torno al concepto de "meta" (PERVIN, 1989), junto a las aportaciones de lo que podríamos denominar "movimiento narrativo en psicología" (BRUNER, 1991, 1996, 2001; SARBIN, 1986), parece que se ha producido un notorio y alentador avance en esta dirección. 
en sus raíces comunitarias y culturales, y a partir de aquí habrá de elegir, tendrá que decidir qué hace con su personalidad, y afrontando sus propias contradicciones, tratando de superarlas, finalmente irá construyendo, reconstruyendo, su propia identidad (Honess y Yardley, 1987). Por esta razón, tiene sentido subrayar la noción de "identidad personal", en tanto que personalidad escogida, como un constructo autónomo, aunque pudiera quedar circunscrito legítima e igualmente al más amplio, vasto y cada vez más complejo concepto de personalidad humana ${ }^{15}$.

La comprensión que uno tiene de sí mismo es una de las fundamentales creencias que inciden en la configuración del carácter. La idea que tiene uno de sí mismo, de los roles con los que se identifica, de los valores morales o culturales que admite, puede determinar los modos de sentir y de actuar, posibilitando nuevos comportamientos del sujeto. O sea, el dinamismo propio del proceso identitario de la persona puede modificar la conducta habitual del sujeto o, si se quiere expresar de otro modo, su carácter. Desde su antropología metafísica, cuando se ocupó del estudio de la personalidad como modo de ser, Xavier Zubiri también subrayaba esta aperturalidad del ser humano, que no deja de ser apertura a lo que no se es: "La personalidad "es" estando optativamente abierta a lo que quiero ser" $(1986,176)$. El adolescente, el joven, o el adulto que no se resigna a lo factual, imaginan aquello en que les gustaría transformarse y aquello en que temen convertirse (Markus y Nurius, 1986).

Hay un interés creciente en las actuales ciencias del comportamiento por la conducta intencional y dirigida a meta, o sea, por el modo en que las personas trasladan la idea de una meta a la acción, aunque la manera en que un sujeto organiza la acción y lo manifiesta no es una preocupación inédita hasta el momento ${ }^{16}$.

15. FiERro, frente a los enredos del lenguaje que pueden provocar las numerosas acepciones de identidad, afirma: "Excepto para la identidad lógica, para el resto de las acepciones personalidad vale tanto como identidad y no se presta a tantos equívocos de prestidigitación semántica" $(2002,266)$.

16. En efecto, en esta línea habría que incluir las clásicas aportaciones de Tolman sobre conductas intencionales en animales, de Lewin sobre el nivel de aspiración y de Rotter acerca del aprendizaje social, aunque lo cierto es que estos modelos del valor-expectativa no han llegado a integrarse en un modelo completo de conducta intencional orientada a meta. Edward Chace Tolman (1932), muy adelantado a su tiempo, subrayó la importancia de los procesos cognitivos por encima de las conexiones estímulo-respuesta. Su conductismo intencional enfatiza un enfoque del aprendizaje centrado más en la estructura de la conducta y en su orientación a meta que en los rasgos más mecánicos y reflejos del comportamiento. Los factores cognitivos en el aprendizaje son decisivos, según Tolman. Los animales aprenden mapas cognitivos del entorno, o expectativas conductuales en función de sus resultados. Tolman se anticipó al procesamiento de la información y su perspectiva de la mente humana. Kurt LEWIN (1944), en sus trabajos sobre el nivel de aspiración, donde acentuaba las expectativas y los valores (valencias, valores positivos o negativos asociados a las metas) en el comportamiento humano, también propuso una teoría sobre la conducta dirigida a meta. Según Lewin, los individuos establecen objetivos o metas para su comportamiento futuro, teniendo presente sus valoraciones sobre la dificultad de la tarea y sobre sus propios niveles de capacidad. El sentimiento de éxito se vincula a una evaluación entre el nivel de aspiración establecido, la meta, y el resultado alcanzado; el mayor éxito se asocia a los niveles más altos de aspiración, lo que significa el planteamiento de metas más difíciles. Contrariamente, un 
La conducta del ser humano es muy compleja, en su determinación influyen muchos elementos, pero una atenta mirada al comportamiento humano nos desvela que la mayoría de sujetos presenta una conducta general relativamente organizada. Esa estructura organizada que denominamos conducta lo es respecto de algún referente. Puede admitirse que se trata de una organización orientada hacia meta, dirigida al logro de algún objetivo, para lo cual el sujeto elabora estrategias o planes de acción específicos.

Diversos programas de investigación han tratado de exponer modelos representativos del comportamiento humano resaltando la relevancia de su estructura intencional. Todos estos estudios se centran en la función que cumplen las metas, los objetivos, los proyectos, en el comportamiento y, a través de él, en la personalidad misma. Son criterios de referencia con los que puede irse comparando la propia acción. Little (1989) ha investigado sobre los "proyectos personales" como metas específicas de los individuos. Un proyecto personal no es más que un extenso conjunto de acciones personalmente importantes que persiguen una meta determinada. De este modo, podemos considerar como proyecto personal actividades muy diferentes, desde las más simples, propias de la vida cotidiana, hasta las relacionadas con los más altos propósitos ${ }^{17}$. También cabe destacar las investigaciones de Emmons (1989) sobre las "aspiraciones personales", que son aquellos tipos de metas característicos que un sujeto espera lograr en distintas situaciones. Se trata, pues, de algo que la persona quiere conseguir, experimentar, o de algo que pretende evitar. Emmons describe la "aspiración personal" como un patrón coherente de aspiraciones a meta, representativo de lo que un sujeto típicamente está intentando realizar. De las investigaciones de Emmons se desprende que las

mayor fracaso se vincula a no lograr niveles bajos de aspiración, es decir, a no llegar a superar las metas más fáciles. Julian RơTter (1954), considerando la importancia para el aprendizaje tanto de las variables cognitivas como de las variables motivacionales y de reforzamiento, elaboró un modelo teórico de la personalidad fundada en el valor-expectativa y en el aprendizaje social. Según Rotter, la probabilidad de una conducta específica en una determinada situación, el potencial de comportamiento, es una función de la expectativa de la recompensa y del valor que a ésta se atribuye. Tanto la expectativa como el valor son subjetivos, dependen de cada sujeto en una situación dada. La conducta del sujeto está, pues, en función de la situación, pero al mismo tiempo es el propio sujeto quien define tanto la expectativa como el valor del resultado asociado a la situación. Rotter también insistió en la importancia de las "expectativas generalizadas", referentes a aquellas expectativas que propenden a trascender las situaciones específicas; en otras palabras, los sujetos, en función de su biografía, de su recorrido existencial, tienen creencias generalizadas sobre ellos y acerca del mundo.

17. Visto así, cada sujeto tiene en un momento dado varios proyectos personales (según el método de Análisis de Proyectos Personales empleado por Little, típicamente, los sujetos suelen reconocer unos quince proyectos aproximadamente). La perspectiva de Little es palmaria: estudiar cómo afrontan sus vidas las personas en realidad. Más que como unidades separadas, los proyectos personales constituyen sistemas. Aunque los proyectos personales admiten una estructura jerárquica, debido a sus múltiples interconexiones pueden contemplarse mejor como una estructura de red. Little encuentra una relación entre bienestar individual y valoraciones de los proyectos bajas en estrés y altas en resultado positivo y control. 
emociones positivas se asocian a aspirar a metas relevantes y a la sensación de haber cumplido las aspiraciones en el pasado, mientras que las emociones negativas se asocian con la ambivalencia, el conflicto y una baja probabilidad subjetiva de éxito en lograr las aspiraciones personales ${ }^{18}$. Por su parte, Nancy Cantor (1990, 1994) ha puesto énfasis en los aspectos adaptativos del funcionamiento de la personalidad, específicamente aquellos aspectos adaptativos del funcionamiento cognitivo. Subraya las competencias cognitivas que los sujetos pueden emplear cuando intentan resolver problemas de la vida cotidiana, o dicho de otro modo, pone el énfasis en la "inteligencia social" de los individuos. Esta investigadora está interesada por el estudio de la personalidad dentro de un contexto, de ahí que se dé particular importancia a los significados idiográficos que las situaciones y los acontecimientos tienen para los sujetos. Cantor acentúa la importancia de ciertas funciones cognitivas: discriminaciones entre situaciones, representación de metas y desarrollo de planes para lograrlas, representación de un yo con una historia pasada, representación de posibles yoes para el futuro, desarrollo de estrategias de afrontamiento y mecanismos de autorregulación. Los trabajos de Cantor desarrollan un modelo sobre la personalidad en el que los pensamientos, sentimientos y esfuerzos de los sujetos adquieren forma y función desde las tareas vitales que realizan y las estrategias cognitivo-conductuales que aplican cotidianamente. De este modelo se deduce una preocupación por la inteligencia social en la misma medida en que los individuos piensan creativamente sobre su propio potencial y sobre posibles mundos en los que podrían vivir.

Afirmando que una teoría de la personalidad debe asumir tanto la estabilidad como el cambio de la conducta en la vida cotidiana de cualquier ser humano, Lawrence A. Pervin $(1983,1989)$ propugna la formulación de una "teoría de metas" como la más plausible comprensión del comportamiento humano. El carácter

18. El enfoque de Emmons es compatible con el modelo de control, de CARVER y SCHEIER (1990). Este modelo utiliza principios de funcionamiento de sistemas de control y resalta las diferencias individuales en la medida en que los sujetos prestan atención a los aspectos privados o públicos del self. Se distingue entre autoconciencia privada y autoconciencia pública. Las personas con una elevada autoconciencia privada tienden a tener sentimientos más intensos y a ser más claros acerca de sus sentimientos que las personas con una baja autoconciencia privada, también suelen tener conceptos del self más desarrollados. Aquellas personas que tienen una alta autoconciencia pública tienden a ser más sensibles ante las solicitudes y señales de los demás. Para este modelo, los sujetos son impelidos a controlar su conducta respecto de la exigencia. En este sentido autorregulador, hay proximidad con el modelo de Bandura sobre exigencias de meta y autorregulación, en consonancia con su teoría sociocognitiva. Las creencias de autoeficacia, para Bandura, cumplen una función capital en el proceso de autorregulación de la conducta del sujeto. Una baja valoración de la autoeficacia puede obstaculizar los procesos cognitivos que son básicos para progresar en el logro de la meta. Afirma Bandura que las personas son más fieles a las metas elevadas, que suelen preferir antes que las en apariencia más fáciles y de nivel más bajo. Pero añade que la mejor manera de avanzar en el logro de las metas es delimitándose submetas o metas subordinadas, fines más inmediatos y específicos que van haciendo el trayecto más soportable y realista. Como dice el propio Bandura $(1989,44)$, "aspirar a metas inalcanzables es condenarse a un fracaso implacable". 
estructurado y organizado de la conducta sugiere que está orientada a objetivos o metas. Estas metas pueden ser de mayor o de menor relevancia, a largo o a corto plazo, simples o complejas. Las metas presentan componentes cognitivos (representaciones mentales de las metas), afectivos (sentimientos y emociones ligadas a las metas) y de conducta manifiesta (planes de acción para conseguir las metas); pero es el componente afectivo de las metas el que determina finalmente su poder motivacional, señala Pervin. Las metas están siempre presentes en el sistema en que consiste la conducta humana. La dinámica del funcionamiento del sistema de metas conlleva la activación, mantenimiento y finalización de la actividad orientada a meta. El papel de las emociones en la dinámica del sistema de metas parece crucial tanto para comprender cómo se fijan las metas -en virtud de la asociaciones emocionales que el sujeto va realizando con determinadas personas, lugares, cosas, etc.-, como para tratar de describir cómo se desarrollan los sistemas de metas.

Progresivamente, la perspectiva de la ciencia cognitiva ha ido incidiendo en la importancia de las variables afectivas y motivacionales, y no únicamente en las estrictamente cognitivas. Es muy interesante el concepto de "selves posibles" (sí mismos posibles) (Markus y Ruvolo, 1989), que viene a significar qué cree el sujeto que llegará a ser, qué le gustaría ser y qué no le agradaría llegar a ser. Los selves posibles sirven para organizar la información, pero sobre todo tienen una notable influencia motivacional que nos conduce hacia determinadas metas y no hacia otras. El enfoque cognitivo social del self(sí mismo), actualmente, destaca la importancia de las consecuencias afectivas, motivacionales e interpretativas de las estructuras del self, así como de la función que desempeñan en la construcción misma del self. No cabe duda de que estas variables se muestran de manera diferente entre las personas, pero también entre grupos culturales distintos.

En la interacción que se da entre estabilidad y cambio, entre estática y flujo, de la conducta, se hallan los interrogantes abiertos acerca de en qué consiste ese fenómeno que denominamos personalidad. Que los seres humanos tenemos la capacidad de proyectar conductas, de aspirar a ciertos ideales, valores, parece algo claro, a la luz de los más recientes enfoques científicos sobre la personalidad. Que esta capacidad no sea un espejismo, un mero reflejo de determinantes biológicos o sociales, temperamentales o situacionales, sino que responda a una elaboración propia, por limitada o modesta que sea, que refleje la existencia viva de un espacio de construcción autónoma, significa admitir la existencia de fenómenos de libertad posible en el sujeto (Fierro, 2002). La personalidad escogida, la que podemos elegir, dentro de los límites de la acción humana, enfatiza la apertura de posibilidades del sujeto. Desde la asunción de la existencia real de tales fenómenos de libertad es como tiene pleno sentido hablar de «identidad personal». Identidad personal en tanto que personalidad escogida. Somos lo que somos y nuestras posibilidades, una mezcla de realidad e irrealidad, de actualidad y de posibilidad, de presente y de futuro. Si nuestro comportamiento está, como parece, dirigido a metas, la riqueza de posibilidades que tengamos dependerá de nuestros recursos. Aquí está el papel crucial de la educación, ella es la que puede proporcionar 
recursos al sujeto para aumentar su arco de posibilidades de realización humana. La personalidad es escogida en tanto que vamos eligiendo unos valores u otros, unos ideales u otros, unas conductas u otras; el valor de esa elección estará en función del criterio que se emplee, y éste dependerá del potencial de recursos con los que cuente el sujeto. La identidad personal puede considerarse esa personalidad escogida, esa personalidad dinámica y fluida que nos va definiendo paulatinamente a través de nuestras acciones, pensamientos y sentimientos. El valor de la identidad es directamente proporcional a la calidad de los recursos disponibles que posea el sujeto, es decir, a la calidad de aquellos criterios humanizadores con los que el sujeto elabora sus procesos identitarios.

Vamos construyendo el significado, en tensión entre el mundo intersubjetivo y la experiencia del vivir, y así vamos construyendo la identidad, en buena medida definida por la posibilidad misma de orientarse en el mundo de acuerdo a ciertos principios, conceptos, patrones. La identidad consiste en una construcción narrativa personal en la que la forma de forjar el propio mundo se convierte en modo de reconstruir la propia vida: "El relato se completa por el lado del futuro. Yo soy el que fui se complementa con yo soy el que seré" (Fierro, 2002, 306). La identidad no sólo es contingente, sino también precaria, puesto que, en última instancia, posiblemente queda más definida por lo ideal que por lo real, más por aquello que aún no hemos logrado ni llegado a ser, que por lo que somos o hemos alcanzado.

\section{AUTODETERMINACIÓN Y EDUCACIÓN}

Lo importante en la perspectiva de la identidad como personalidad escogida es esa dimensión relacionada con lo que queremos ser y hacer. Aunque pleno de incertidumbre, el porvenir es susceptible de conocimiento previo bajo el enfoque de las metas, de los proyectos personales. Realmente, los planes personales aspiran a ser una historia anticipada de futuro. Y en nuestra vida cotidiana, a través de multitud de actos mínimos, coadyuvamos a entretejer los diversos hilos del discurrir de nuestra existencia. El lugar de articulación entre el pensamiento y la acción es lo que podemos denominar decisión. Pero ésta no es un mero acto, sino un proceso. Los procesos de decisión en terminología clásica recibirían el nombre de voluntad -a ésta también se refieren los procesos implicados en las necesidades, la motivación y la activación-. Aunque muchas acciones no corresponden a procesos formalmente deliberativos, las acciones de mayor relieve sí, aquellas relacionadas con la resolución de conflictos, el afrontamiento de adversidades y las encaminadas a la satisfacción de determinadas necesidades del sujeto. Aquí topamos con el meollo de la cuestión: ¿qué y cómo es el proceso humano de decisión?

El sujeto toma decisiones en condiciones de racionalidad incompleta. Suelen tomarse en condiciones de riesgo, de incertidumbre, y sin información suficiente sobre la verdadera magnitud del riesgo. Las decisiones se toman a menudo bajo estimaciones y razonamientos escasos, sobre la inestabilidad que comportan 
preferencias cambiantes, no fijadas definitivamente. Los procesos de decisión constituyen un auténtico laberinto para el ser humano, en el que no es extraño que se pierda (Rubin, 1986). Las decisiones importantes de la vida, elegir una profesión, medir las probabilidades de éxito de vida en común con alguien, calibrar un cambio de residencia a otro país u otro lugar distante del que habitamos..., las adoptamos bajo el prisma de la incertidumbre, desde la incapacidad personal de poder estimar todas las probabilidades. Pero las numerosísimas pequeñas decisiones de la vida de cada día también están impregnadas de incertidumbre, porque nuestras preferencias o valoraciones son cambiantes, a la par que los acontecimientos fluyen mientras esperamos para decidir, con lo que pueden afectar de nuevo a nuestras estimaciones. Tomamos decisiones en un mundo de acontecimientos y de encadenamientos de probabilidades, de cuya posibilidad real no tenemos certeza. Elegimos en condiciones de información incompleta, sesgada subjetivamente y con preferencias variables. Esto nos convierte a todos en excelentes profetas del pasado: "ya lo decíamos", manifestamos cuando el hecho se ha consumado. En estas condiciones, tomar decisiones es un factor inequívoco de estrés para casi todo el mundo, que, por otra parte, se ve impelido constantemente a tener que decidir de una u otra manera, puesto que incluso no elegir ya es un modo de elegir (Savater, 2004).

La vieja idea de libertad o libre albedrío como indeterminación se debilita seriamente cuando consideramos que el sujeto es una agencia de conducta con el suficiente grado de complejidad sistémica como para que en él unos elementos determinen a otros y para que exista una determinación interna, un determinado dispositivo de control (Fierro, 2002). Ser libre es tomar decisiones, y serlo racionalmente es tomar decisiones con la mayor carga de inteligencia posible. Los actos libres son también determinados, mejor dicho, autodeterminados. La conducta libre es comportamiento autodeterminado, decidido por uno mismo, autorregulado. A mayor importancia de la decisión que hemos de tomar, más claro parece que «decidir algo" es "decidirse uno a algo" y autodeterminarse. Nuestro proyecto queda definido por la autodeterminación, pero también nosotros mismos. La identidad personal en gran medida es una invención de sí mismo. En el dominio del autoconocimiento definirse es tanto como decidirse. Ignoramos quiénes somos hasta que nos construimos gracias a las decisiones que tomamos. En la medida en que supone autodeterminación, el proceso de decisión, la decisión, es el centro de la conducta orientada a meta, la que proporciona sentido a la acción y, finalmente a la vida. Frente a la enajenación, contra la alienación, la autodeterminación posible, el autogobierno de la propia vida dentro de los cortos márgenes en que podemos disponer de ella, proporciona significado a nuestra existencia. Entraña riesgos, siempre se da envuelta en panoramas inciertos; pero empeñarnos en proveer, mediante la educación, los mejores recursos para la autodeterminación posible constituye una decidida posición pedagógica esperanzadora. Sobre todo, si consideramos que el hombre ha usado hasta el presente una pequeña parte de las posibilidades de su cerebro, de su mente: "salvo una posible catástrofe, el ser humano no se halla en 
el límite de las posibilidades cerebrales/espirituales históricas de las sociedades y antropológicas de la evolución humana" (Morin, Roger y Motta, 2003, 139).

La acción humana no sólo está vinculada al despliegue de conductas instintivas, sino que también lo está, significativamente, al registro simbólico de posibilidades de acción que abren su conducta a lo inédito, a lo nuevo, a lo desconocido, más allá de los patrones de comportamiento establecidos en el pasado por los miembros de su especie. El más precipuo mecanismo del que disponemos para desarrollar nuestra capacidad de elegir, para nuestra liberación, que bien entendida es autodeterminación como ya hemos señalado, a no dudarlo, es la educación.

\subsection{Dominios formativos personales para la autodeterminación posible}

Los diferentes proyectos educativos personales ${ }^{19}$, necesariamente diferenciales, que puedan emprenderse, incluyendo las diversas narrativas del yo, para propiciar la búsqueda y la construcción de la identidad, promoviendo los resortes pedagógicos necesarios, oscilarán entre dos tendencias: la autoverificación o consistencia y la autoestima. La consistencia trata de hallar armonía entre las percepciones del sí mismo y entre las percepciones del sí mismo y la información nueva que le llega. La autoestima, en cambio, hace referencia al intento de encontrar información que eleve, o al menos mantenga, el nivel ya alcanzado. Por la autoverificación tratamos de ser conocidos por quienes somos o quienes creemos ser, por la autoestima procuramos ser conocidos por quienes nos gustaría ser. Aquí se cruzan dos necesidades: la necesidad cognitiva de consistencia y la necesidad de autoestima. Las investigaciones realizadas parecen poner de manifiesto que hay diferencias individuales tanto en la necesidad de autoestima como en las condiciones en las que la necesidad de autoverificación o de autoestima son mayores (John y Robins, 1994). Si el contexto delimita una necesidad de realidad pueden predominar los procesos de consistencia, pero si la necesidad de autoestima es acuciante o el reclamo de realidad es tenue, pueden pasar a primer plano los procesos de autoestima. Sin embargo, en las investigaciones de Cantor (1994) hay una invitación a trascender las discusiones sobre consistencia, para tratar de comprender los procesos de personalidad subyacentes a los esfuerzos individuales para participar en las tareas incesantemente cambiantes de los contextos vitales. La flexibilidad de la personalidad y el aprendizaje son más importantes para el bienestar del sujeto que la estabilidad o la consistencia, puesto que las tareas vitales cambian del mismo modo que lo hacen las oportunidades y restricciones que se van descubriendo en las múltiples situaciones que configuran el decurso de la vida.

19. Proyectos vinculados a espacios de acción. GARCía del Dujo y MuÑoz Rodríguez (2004, 275) proponen acertadamente la sustitución de la idea abstracta de espacio por el concepto de espacio de acción, considerándolo "como algo inherente a la acción humana y, por consiguiente, a la acción educativa, y no tanto como una variable externa que influye en ésta". 
Haciéndonos eco de la trascendencia de las variables afectivas y emocionales, y no sólo cognitivas, en el comportamiento humano, tratamos seguidamente de establecer, sin ánimo de cerrar la discusión, sino más bien de abrir el debate sobre la misma, aquellos dominios formativos personales desde los que poder construir la identidad, en clave de personalidad escogida ${ }^{20}$. Una concepción sistémica del sujeto nos conduce necesariamente a una advertencia previa: los dominios que delimitamos a continuación, en realidad, están interrelacionados entre sí, respondiendo a una estructura de carácter complejo, tal vez no jerarquizada e imperfectamente unificada, pero referente a un mismo sujeto en el que, de algún modo, se produce el bucle identitario.

\subsubsection{Dominio de la actividad mental}

Desarrollar una mente activa es un aspecto básico para la construcción autónoma de la identidad. Este desarrollo conlleva actividad espontánea por parte del sujeto, capacidad de descubrimiento, curiosidad intelectual, sentido crítico y capacidad para resolver problemas. La actividad en el ser humano aflora naturalmente, sólo precisa de la libertad necesaria para facilitar el despliegue de todas sus capacidades. El niño es curioso y activo, esa tendencia innata debe ser estimulada convenientemente desde el punto de vista pedagógico. Es preciso ayudar al niño a que abra sus sentidos, a que explore la realidad y pueda construir su mundo. Como ha escrito Max van Manen (2004, 23):

Nombrar el mundo constituye una poderosa actividad humana. "¿Qué es esto?" no sólo pregunta por un nombre concreto. El niño que lo pregunta busca algo más: que una persona mayor hable del mundo. "QQué es esto?" pide tiempo pảra el diálogo, tiempo para pensar, para sorprenderse, para maravillarse. Por eso, el adulto, en vez de limitarse a identificar los objetos que el niño señala, debería detenerse en las distintas dimensiones semánticas de estos objetos.

20. La conceptualización de la identidad personal y la delimitación de los dominios formativos para su desarrollo, que exponemos en este trabajo, devienen en la configuración de un modelo educativo para la construcción de la identidad del sujeto, en tanto que plan estructurado para el diseño, desarrollo e implementación de la acción formativa de los procesos de identidad. En dicho modelo caben diversas estrategias, es decir, diferentes formas de proceder. Queda fuera del propósito del presente artículo el análisis de tales estrategias. En cualquier caso, señalaremos brevemente, con sentido globalizador, algunas que pueden considerarse fundamentales al respecto: 1) estrategias para la formación en actitudes y valores, dado que mediante el proceso de valoración se adquiere y configura el propio sistema de valores y la personalidad del sujeto; 2) la discusión como estrategia de desarrollo educacional, estrategia que incluye tanto el aprendizaje cognitivo como el afectivo y social; 3) estrategias para el desarrollo de habilidades de pensamiento de alto nivel, puesto que tales destrezas indican las diferencias entre los sujetos con capacidad de iniciativa y creativa y aquellos otros que sólo reciben las ideas de los demás; 4) estrategias de ayuda y cooperación, puesto que compartir experiencias formativas implica la posibilidad de progreso y aprendizaje personal por la "transmisión horizontal" de conocimientos, intereses y valores. 
La elaboración de un conjunto de creencias acertadas sobre el mundo, sobre los demás y acerca de uno mismo, precisa de la puesta en práctica de la capacidad reflexiva y del sentido crítico. El desarrollo de estas capacidades depende de la calidad de las interacciones que el sujeto mantiene con el medio cultural. Más que de cabezas llenas, se trata de cabezas bien organizadas, capaces de abordar los problemas de la realidad desde la generalidad y la concreción, desde la globalización y la contextualización (Morin, 2001). Actuando sin dogmatismos, ni fanatismos, el sujeto crítico da razón de su pensamiento y de su acción, de su vida, haciéndose inmune contra el error y la falta de lucidez. Intimamente unida a la capacidad reflexiva y al sentido crítico, se halla la flexibilidad mental, esto es, poseer pautas de actuación que nos permitan cambiar nuestras representaciones mentales (ideas, conceptos, aptitudes, relatos, teorías acerca del mundo), si llega el caso (Gardner, 2004). Una mente flexible precisa tener la suficiente capacidad de relación de fenómenos y de comprensión del mundo como para adoptar nuevas orientaciones personales ante situaciones determinadas que pudieran surgir en la vida. La resolución autónoma, positiva y constructiva, de problemas es fundamental para desarrollar un pensamiento propio. Dice Howard Gardner $(2004,227)$ que "de todas las especies que pueblan la Tierra, el ser humano es la que se ha especializado en el cambio mental voluntario". Y agrega, con razón: "La mente humana es una creación humana y todas las creaciones humanas se pueden cambiar. No tenemos por qué reflejar de una manera pasiva nuestra herencia biológica o nuestras tradiciones culturales e históricas" $(2004,240)$. Evidentemente, a nosotros corresponde la responsabilidad de usar los instrumentos y recursos cognitivos disponibles con fines egoístas o altruistas.

\subsubsection{Dominio de la creatividad}

Poseer creatividad es descubrir posibilidades en la realidad: "El desarrollo de la inteligencia creadora debe ser el centro de una pedagogía de la posibilidad, (Marina, 2004, 154). La creatividad, como fenómeno que se manifiesta en todos los ámbitos, se demanda desde todos los niveles. Un panorama natural, social y cultural incesablemente proteico nos reclama nuevas respuestas para resolver los innumerables problemas que de continuo de él emanan. Con esta intención, se ha distinguido entre pensamiento vertical, el que alcanza soluciones mediante planteamientos lógicos, y pensamiento lateral, o pensamiento creativo, capaz de aportar nuevas ideas al pensamiento lógico para aumentar su eficacia (De Bono, 1998). Los sucesos fundamentales para la existencia y cambio de un sistema dinámico, como el que constituye el ser humano, dependen de procesos inventivos, creativos, de fenómenos de "autopoiesis" (Rodríguez, 1997). En el dinamismo propio del hombre se dan situaciones que exigen algo más que la simple adaptación ya conocida al contexto, reclaman poner en juego sus potencialidades creadoras. Estas posibilidades creativas están al alcance, con diferente intensidad y amplitud, de todos. 
Cada sujeto puede y debe reclamar su condición de autor, su capacidad inventiva. El devenir planetario de la humanidad está signado por la incertidumbre, pero ésta solicita la esperanza. De la conciencia acerca de las carencias del ser humano y de sus manifestaciones más terribles, nace la desesperanza. Una dialógica entre desesperanza y esperanza hace plantear a Morin, Roger y Motta (2003), cuando perfilan el eje estratégico directriz para civilizar la civilización, varios principios de esperanza en la desesperanza: principio vital, principio de lo inconcebible, principio de lo improbable, principio del topo, principio de salvataje y principio antropológico. En este punto, vale la pena recordar los principios de lo inconcebible, relativo a que todas las grandes transformaciones o creaciones fueron impensables antes de que se produjeran, y de lo improbable, referente a que todos los acontecimientos felices de la historia fueron previamente improbables.

\subsubsection{Dominio emocional}

Algo sabemos con cierta claridad: la región emocional es el sustrato sobre el que se desarrolló y evolucionó el cerebro racional, y los centros emocionales inciden en el funcionamiento global del cerebro. No siempre la razón controla los sentimientos y las pulsiones. Nuestras emociones y sentimientos básicos forman parte de nuestra biología, aunque es el ambiente cultural el que definitivamente modula las manifestaciones o inhibiciones emocionales, en función de los significados culturales de los grupos concretos en los que el individuo crece y experimenta su desarrollo. La dimensión emocional del sujeto está en función de su equipamiento biológico, de la estructura social y la cultura, así como del desarrollo afectivo que experimente. La educación emocional puede contribuir al equilibrio afectivo necesario para la configuración positiva de la identidad (André y Lelord, 2002). La "Sabiduría emocional" de la que se habla actualmente no hace sino poner el acento en la importancia de la afectividad para la vida personal y comunitaria. El dominio formativo de las emociones puede articularse en diversas áreas que, en realidad, constituyen un entramado real en el ámbito de la afectividad del sujeto (Bisquerra, 2000; Torrabadella, 1997). De esta forma, podríamos señalar: el autoconocimiento emocional y su comunicación a través de los diversos lenguajes al alcance del ser humano, el reconocimiento de los sentimientos y emociones de los otros, la capacidad de autorregulación emocional, los procesos conducentes a la autoestima del sujeto y la práctica de las relaciones empáticas, interpersonales.

\subsubsection{Dominio del afrontamiento y del bienestar subjetivo}

Infortunadamente, en la vida es fácil encontrarse con adversidades de distinto tipo, generadoras del suficiente estrés como para repercutir más o menos seriamente en el sujeto. La conducta activa (reactiva y adaptativa) ante la adversidad constituye el dominio del afrontamiento. Desde el afrontamiento se trata de 
gestionar los conflictos provocados por las situaciones adversas del mejor modo posible, lo cual no significa necesariamente controlar y someter las circunstancias desafiantes para el sujeto (Barlow, 2000). En cierto modo, afrontar es establecer una "negociación" con la realidad adversa, ya sea ésta física o social. El afrontamiento exige distinción entre el hecho objetivo adverso, que requiere solucionar ese problema concreto, y la percepción subjetiva de la adversidad, que demanda manejar ideas y emociones. La superación de los posibles obstáculos que la vida nos pueda deparar parece una exigencia formativa de primer orden en una sociedad altamente compleja, donde las relaciones humanas no escapan a los altos niveles de incertidumbre que todo lo impregnan. En cierto modo, el afrontamiento supone sacar fuerzas de donde no las hay, por eso una pedagogía del esfuerzo, en este sentido, es muy importante. Y esta pedagogía se inicia en las primeras contrariedades que el niño sufre en su ámbito más próximo. En términos análogos, relativos a la educación familiar, se ha hablado de "educar en la contrariedad" (Altarejos, Martínez, Buxarrais y Bernal, 2004, 127).

Es muy importante experimentar el bienestar subjetivo, las emociones agradables, con aquellas cosas que hacemos cotidianamente en los distintos ámbitos de la vida. Los procesos identitarios se ven afectados por múltiples experiencias insatisfactorias que se producen en los diversos entornos, y particularmente en los específicamente educativos (vivencias escolares negativas de muchos estudiantes, malestar docente, vida estresada de muchos niños en la escuela, situaciones de marginalidad que viven los excluidos del sistema...). En este contexto, urge una reorientación de la preocupación por la experiencia de la educación en sí misma y por el sentido que ella tiene para el sujeto. También se trata de abrir la experiencia del sujeto a la dimensión poética de la existencia y a la dimensión estética de la vida que nos dan las artes, porque "en toda gran obra de literatura, de cine, de poesía, de música, de pintura, de escultura, radica un pensamiento profundo sobre la condición humana" (Morin, 2001, 56). La calidad estética de la existencia contribuye a esclarecer, elevándolo cualitativamente, el dinamismo identitario del sujeto.

\subsubsection{Dominio de la iniciativa personal y del emprendizaje}

Como ha manifestado Michael Fullan $(2002,153)$, refiriéndose principalmente a los protagonistas dentro del sistema educativo, "la capacidad de controlar el cambio es una aptitud esencial en la sociedad posmoderna". No sustituye, dice Fullan, el enfoque en el sujeto al cambio del sistema, pero añade que es la vía más adecuada para conseguirlo. El cambio nos sobreviene, no podemos no elegirlo, sí podemos no obstante elegir la forma de responder al cambio. Este modo de respuesta se halla vinculado al crecimiento personal, cuestión que es opcional. El dinamismo en los distintos ámbitos sociales reclama individuos con elevados grados de autogestión, de responsabilidad y de compromiso, pero también con capacidad de innovar y de emprender. Hacer frente a las transformaciones del 
medio implica la necesidad de un aprendizaje permanente que proteja al sujeto de los riesgos del anquilosamiento y de las múltiples caras de la marginación ${ }^{21}$. Pero incluso se trata de ir un poco más lejos, no ya de evitar la exclusión de la dinámica social y cultural, sino de ser capaz de tomar iniciativas, de emprender nuevos caminos aún no hollados, de abrir las expectativas personales y sociales. La iniciativa personal conlleva un interés real por el desarrollo y mejora de las habilidades, por la implicación en tareas que entrañan retos, por la actividad y el desempeño individual. Relacionada con la iniciativa se encuentra la sensación de poder en el sujeto, es decir, con la apercepción del individuo de poder hacer cosas por sí mismo, de tener confianza en sus propias posibilidades. Vinculada a la autoconfianza, la capacidad de autoafirmar los propios derechos, la asertividad, es un aspecto igualmente importante para intentar ser uno mismo ante los demás, verdadero antídoto contra el peligro de la conformidad.

En este sentido, se habla en los últimos tiempos de incentivar una cultura del emprendizaje, una cultura viva, innovadora. Desarrollar la capacidad emprendedora del sujeto se hace cada vez más necesario en un mundo que exige con premura el emprendizaje como resorte educacional que requiere una acción pedagógica compleja, constante y gradual a lo largo del tiempo. El emprendizaje se vincula centralmente a un pensamiento sistemático para planificar y liderar proyectos en entornos sometidos a cambios incesantes (Prat, 1986). La aventura de emprender en esta época no es un lujo restringido a una selecta porción demográfica, es más bien una exigencia para toda vida personal que aspire a serlo auténticamente. Ciertamente, emprender es crear nueva riqueza social. Una cultura del emprendizaje busca alentar la capacidad de iniciativa de los jóvenes para generar en ellos un sentido de autonomía que les permita afrontar los desafíos que el nuevo mercado de trabajo del autoempleo les impone. Esta cultura, en cualquier caso, puede fomentarse desde edades tempranas, cuando los sujetos empiezan a tomar conciencia de su personalidad y tratan de alguna manera de iniciar el autodescubrimiento de sus potencialidades.

21. La construcción de la identidad personal se ve hoy amenazada seriamente, debido a las transformaciones del sistema educativo y del currículo actuales. Considerando la perspectiva sistémica de los cambios -interacciones entre los subsistemas educativos y entre los sistemas educativos y otros sistemas: económico, tecnológico, cultural...-, pueden advertirse diversas tiranteces en los sistemas educativos (información contra cultura, tecnología contra cultura, formación de competencias específicas contra competencia humana...) que pudieran condensarse en la sustitución de lo que presenta potencial de permanencia o duración por lo efímero e inmediato y de lo consistente por lo epidérmico y fragmentado. Si a esto se agrega la problemática derivada de la nueva conceptuación del espacio (crisis del colectivo Estado-nación y desarrollo de la sociedad de redes con sus "brechas"...) no es difícil apercibirse de los riesgos actuales que existen para la construcción de la identidad personal (VÁzQUEz, 2003). 


\subsubsection{Dominio de la ética}

La inteligencia práctica, aplicada a las cuestiones humanas, finalmente, nos orienta hacia la búsqueda de las preguntas pertinentes y de sus respuestas oportunas, esa "poética del vivir" que, para Sternberg (1997), deriva en "inteligencia exitosa". Y no puede haber cabalmente inteligencia exitosa sin inteligencia moral. La grandeza del ser humano radica en ser capaz de vida moral, o sea, en la preservación y promoción de lo más valioso: la vida personal (Escámez, 1998). La dimensión moral constituye el núcleo de la configuración positiva, humanizadora, de la identidad personal (Bernal, 2003). Partiendo de la complejidad y de la incertidumbre de los fenómenos humanos, lo que es por tanto válido igualmente para el fenómeno moral, el ámbito ético es terreno para la construcción discursiva autorreferida y situacional, dado que los procesos de identidad se configuran necesariamente en los dominios de interacción en que actuamos como sujetos. En el dominio de la ética hay que analizar cómo pueden los individuos acceder a identidades valiosas, o sea, morales, suscitando posibilidades de crecimiento autónomo personal, respetando la voz propia de cada persona, única e irrepetible, y armonizándolo asimismo con la construcción de una comunidad justa. En efecto, la felicidad posible depende también de saber integrarse en un proyecto social, de saber comunicarse con los otros, de tender la mano al otro. Así, la prosocialidad posee un gran valor moral, dado que se refiere a la realización de conductas favorecedoras para otros sujetos, grupos u objetivos sociales, sin que el sujeto agente busque recompensa de tipo alguno. De esta manera, sin perderse las identidades personales, las conductas prosociales aumentan la probabilidad de generar comportamientos solidarios. En este sentido, la pedagogía de la alteridad (Ortega, 2004), como nuevo paradigma para la praxis y la investigación educativas, resulta bien interesante al respecto. Desde este paradigma se contempla la educación como acogida y responsabilidad, facilitándose así el aprendizaje de los valores, el clima moral del aula $y$, en fin, los procesos identitarios mismos de los sujetos reales.

\section{CONCLUSIONES}

La construcción de la identidad personal se produce en interacción con el mundo. La construcción de la identidad se hace desde una dependencia originaria del contexto cultural. Ortega y Gasset (1983, 322, tomo I) lo expresó de forma célebre: "Yo soy yo y mi circunstancia, y si no la salvo a ella, no me salvo yo". No soy yo y el mundo, sino que tanto el mundo como el yo forman una unidad constitutiva de mi vida. Ortega integra a los otros en el sujeto como su propia circunstancia, dato que a menudo se olvida porque de la famosa frase citada con frecuencia sólo recordamos la primera parte. El sí mismo se constituye en interacción, pero asimismo narrativamente. La identidad personal, la identidad del yo, está ligada a la capacidad de poder seguir una narración, como ha mostrado Ricoeur. Y como la acción es acción con otros, el problema del otro está implicado en la narración. La 
narrativa, tan distintivamente humana como el caminar erguido, que nos diría Bruner, viene a ser el medio a través del cual se crea y recrea el sentido de la identidad. El proceso de construcción de la identidad se inicia siempre como participación en el marco de una actividad práctica previa a las circunstancias o condiciones necesarias de descripción o justificación.

Decididamente, a nuestra especie le caracteriza una intensa conciencia y experiencia temporal. Nuestras señas de identidad, antes que otra cosa, son narrativas. La identidad personal consiste en una elaboración narrativa, construcción que realiza, en la medida de lo posible, el propio sujeto. La forma de construir el propio mundo se convierte en modo de reconstruir la propia vida. Aquí reside el poder transformador de los relatos, en su capacidad de volver a construir, de volver a narrar los acontecimientos de la vida en una plataforma de significado nuevo y diferente. El cambio puede producirse como efecto de una nueva narrativa, desde la elaboración de nuevas historias y sus inéditas oportunidades para gestionar de otro modo los problemas de la vida, para afrontar nuevamente la existencia ${ }^{22}$. Uno de los fundadores de la etología humana, el neurólogo y psiquiatra Boris Cyrulnik, refiriéndose al entrenamiento para pensar la condición humana como un cuerpo capaz de producir un mundo virtual y de habitar en él experimentándolo realmente, lo ha expresado poéticamente: "El hombre está embrujado dos veces: por la evolución que construye su mundo y suscita el pensamiento que construye su mundo" (2002, 21).

Jamás ha habido tantas posibilidades de imaginar los modos de ser, pero tampoco ha habido nunca tanta exigencia al individuo. La construcción de la propia identidad nunca había gozado de tantos márgenes, pero al mismo tiempo tampoco había vivido el sujeto con tanta crudeza la angustia vital de su propia configuración personal, la difícil y aun laberíntica búsqueda de su identidad, la posibilidad de invención de sus propios trazos biográficos, porque parece no haber nada establecido a lo que asirse de un modo completamente lúcido, viviendo el sujeto inmerso en un océano de incertidumbres, de contradicciones sistémicas y de paradojas existenciales, que incitan sin descanso a la búsqueda de alivio, aunque éste a la postre no pueda ser más que efímero. Esta posibilidad actual, ese margen de acción, la mayor libertad de la que hoy se dispone, puede provocar miedo, paralización en el proceso de creación que exige la dinámica identitaria de la vida, y, como reacción contraria, el sujeto puede tratar de aferrarse a aquellas identidades "seguras", monolíticas, políticas, religiosas, culturales, que se le ofrecen en el mundo próximo o distante, ya que la eclosión de ansiedades y temores tiene lugar dentro del imaginario social. Hace muchos años, lo dijo Erich Fromm (1980, 278279): «El hombre moderno está dispuesto a enfrentar graves peligros para lograr los propósitos que se supone sean suyos, pero teme profundamente asumir el riesgo

22. El enfoque constructivista también se ha aplicado a la terapia narrativamente (FERNÁNDEZ-LIRIA y Rodríguez-VEGA, 2001). 
y la responsabilidad de forjarse sus propios fines". Recientemente, Savater, refiriéndose a nuestro tiempo, nos ha recordado el peligro del deseo de renunciar a la libertad, de buscar a quien nos descargue de esa pesada carga, de hallar a quien nos permita, "aunque sea viviendo una vida vicaria y en cierto modo humillante, no tener la preocupación, la obligación de elegir permanentemente" $(2004,61)$. Paradójicamente, dado el incremento de posibilidad de acción humana, la sociedad contemporánea dificulta seriamente la búsqueda de la identidad, una búsqueda que cada vez se siente con más apremio. En todo caso, un proceso que ya no estará exento de incertidumbre, puesto que no hay recetas infalibles para la libertad, para la responsabilidad, para la libertad responsable:

No hay ninguna prescripción para la libertad, aunque la constante demanda da lugar a una oferta cada vez mayor de personas dispuestas a escribirla. Y no hay libertad sin ansiedad, aunque al ser éste un sueño perenne de tantos de nosotros, no es raro que tantos de nosotros deseemos que el sueño se convierta en realidad mientras que tantos otros consideran rentable mantener vivo el deseo (Bauman, 2001, 247).

La renuncia a la libertad, o la eliminación de la diferencia por la uniformidad que la reduce a los márgenes, constituyen los caminos para la anulación de la identidad personal. Precisamente, el modo narrativo, que se presupone adquirido naturalmente, como nos dice Bruner (2001), es el más desatendido por las instituciones educativas, pese a ser, posiblemente, el más trascendente en un tiempo de pluralización de las formas de vida y de aceleración de los crecientes movimientos migratorios de población. Atender a la modalidad narrativa implica un cambio del lenguaje de la pedagogía preferiblemente hacia las interpretaciones plausibles antes que a las explicaciones causales, sobre todo cuando éstas exigen artificializar lo que estudiamos hasta tal grado que prácticamente no podemos reconocerlo como representativo de la vida humana. Nuestra capacidad narrativa posee un inequívoco valor pedagógico sobre todo por su carácter proyectivo, en la medida en que la identidad personal la podemos identificar con personalidad escogida, elegida. Más allá de meros reflejos de crónicas fatalistas, sin márgenes para autodeterminación alguna, nuestra capacidad de narración cumple su mejor función cuando es capaz de imaginar otros "yoes" posibles, otros mundos posibles.

De las más dramáticas miserias que ofuscan la posibilidad de elección humana, puede liberarnos la educación. Luchar contra estas miserias, contra la ignorancia o la ceguera, desde la educación, desde los preciados recursos que ella nos puede proporcionar, no constituye un mero combate retórico en pro de la libertad, sino precisamente a favor del buen uso de ella, de la autodeterminación posible, como medio y fin deseable de la genuina condición humana. 


\section{BiBLIOGRAFÍA}

ADLER, A. (1931) Conocimiento del hombre. Madrid, Espasa-Calpe.

AllPORT, G. W. (1966) La personalidad. Su configuración y desarrollo. Barcelona, Herder.

Altarejos, F.; Martínez, M.; Buxarrais, M. R. y Bernal, A. (2004) Familia, valores y educación, en Santos, M. A. y Touriñán, J. M. (eds.). Familia, educación y sociedad civil. Santiago de Compostela, Universidade de Santiago de Compostela, 89-136.

Althusser, L. (1967) Pour Marx. Paris, Maspero.

ANDRÉ, C. y LELORD, F. (2002) La fuerza de las emociones. Barcelona, Kairós.

ÁvILA, R. (1999) Identidad y tragedia: Nietzsche y la fragmentación del sujeto. Barcelona, Crítica.

BANDURA, A. (1989) Self-regulation of motivation and action through internal standards and goal systems, en PERvin, L. A. (ed.). Goal concepts in personality and social psychology. Hillsdale, NJ, Erlbaum, 19-85.

BARLOW, J. (2000) Gestión del estrés. Barcelona, Gestión, 2000.

BARTHES, R. (1974) Análisis estructural del relato. Buenos Aires, Tiempo Contemporáneo.

BaUman, Z. (2001) La posmodernidad y sus descontentos. Madrid, Akal.

BERGER, P. L. y LUCKMANN, T. (1967) The social construction of reality: a treatise in the sociology of knowledge. Middlesex, Penguin Books.

BERnal, A. (2003) La construcción de la identidad personal como proyecto de educación moral. Supuestos teóricos y delimitación de competencias, Teoría de la Educación. Revista Interuniversitaria, 15, 129-160.

BISQUERRA, R. (2000) Educación emocional y bienestar. Barcelona, CISSPRAXIS.

BRUNer, J. (1991) Actos de significado. Más allá de la revolución cognitiva. Madrid, Alianza.

- (1996) The culture of education. Cambridge, Harvard University Press.

- (2001) Realidad mental y mundos posibles. Los actos de la imaginación que dan sentido a la experiencia. Barcelona, Gedisa.

CANTOR, N. (1990) From thought to behavior: "Having" and "doing" in the study of personality and cognition, American Psychologist, 45, 735-750.

- (1994) Life task problem solving: Situational affordances and personal needs, Personality and Social Psychology Bulletin, 20, 235-243.

CARVER, C. S. y SCHEIER, M. F. (1990) Origins and functions of positive and negative affect: A control-process view, Psychological Review, 97, 19-35.

COlom, A. y MÈLICH, J. C. (2003) Narratividad y educación, en AA.VV. Otros lenguajes en educación. Barcelona, ICE de la Universitat de Barcelona, 9-63.

CONwaY, M. (1990) Autobiographical memory: An introduction. Milton Keynes, Open University Press.

Conway, M. y Pleydell-Pearce, C. W. (2000) The construction of autobiographical memory in the self-memory system, Psychological Review, 107 (2), 261-288.

CYRULNIK, B. (2002) El encantamiento del mundo. Barcelona, Gedisa.

DE BONo, E. (1998) El pensamiento lateral. Barcelona, Paidós.

DERRIDA, J. (1984) La filosofía como institución. Barcelona, Granica.

Emmons, R. A. (1989) The personal striving approach to personality, en PERvin, L. A. (ed.). Goal concepts in personality and social psychology. Hillsdale, NJ, Erlbaum, 87-126.

ERIKSON, E. H. (1950) Childbood and society. Nueva York, Norton.

EsCÁmEZ, J. (1998) Educar en la autonomía moral. Valencia, Generalitat Valenciana. 
Fernández-LiRia, A. y Rodríguez-Vega, B. (2001) La práctica de la psicoterapia: la construcción de narrativas terapéuticas. Bilbao, Desclée de Brower.

Fierro, A. (2002) Personalidad, persona, acción. Un tratado de psicología. Madrid, Alianza.

FIVUSH, R. y BUCKNER, J. (2003) Creating gender and identity through autobiographical narratives, en FIVUSH, R. y HADEN, C. A. (eds.). Autobiographical memory and the construction of a Narrative Self. Mahwah, New Jersey, Lawrence Erlbaum Associates, 149-167.

Foucault, M. (1970) Arqueologia del saber. México, Siglo XXI.

Fromm, E. (1980) El miedo a la libertad. Barcelona, Paidós.

Fullan, M. (2002) Las fuerzas del cambio. Madrid, Akal.

Gadamer, H. G. (2002) Acotaciones hermenéuticas. Madrid, Trotta.

García del Dujo, A. y Muñoz, J. M. (2004) Pedagogía de los espacios. Esbozo de un horizonte educativo para el siglo XXI, Revista Española de Pedagogía, LXII (228), 257-278.

GARDNER, H. (2004) Mentes flexibles. Barcelona, Paidós.

GERGEN, K. J. (1994) Exploring the postmoderm: perils or potentials?, American Psychologist, 49, 412-416.

- (1997) El yo saturado. Barcelona, Paidós.

Guidano, V. F. (1991) El sí-mismo en proceso. Barcelona, Paidós.

Heidegger, M. (2003) Ser y tiempo. Madrid, Trotta.

HONESS, T. y YARDLEY, K. (eds.) (1987) Self and identity: Perspectives across the lifespan. Londres, Routledge \& Kegan.

HORKHEIMER, M. (1974) Zur Kritik der instrumentellen Vernunft. Frankfurt a. M., Fischer.

HuSSERL, E. (2002) Lecciones de fenomenologia de la conciencia interna del tiempo. Madrid, Trotta.

INNERARITY, D. (2004) La sociedad invisible. Madrid, Espasa.

JÁuRegui, J. A. (2001) La identidad humana. Barcelona, Martínéz Roca.

JoHN, O. P. y RoBINS, R. W. (1994) Accuracy and bias in self-perception: Individual differences in self-enhancement and the role of narcissism, Journal of Personality and Social Psychology, 66, 206-219.

LACAN, J. (1970) El objeto del psicoanálisis. Barcelona, Anagrama.

LÉVI-STRAuss, C. (1968) Antropología estructural. Buenos Aires, Eudeba.

Lewin, K.; Dembo, T.; Festinger, L. y Sears, P. S. (1944) Level of aspiration, en HunT, J. McV. (ed.). Personality and the behaviour disorders. Nueva York, Ronald, 333-378.

LITTLE, B. R. (1989) Personal projects analysis: Trivial pursuits, magnificent obsessions, and the search for coherence, en Buss, D. M. y CANTOR, N. (eds.). Personality psychology: Recent trends and emerging directions. Nueva York, Springer-Verlag, 15-31.

Luiz, M. y MÉnDEz, M. (2003) Generación de capacidades emprendedoras en la formación universitaria: una visión crítica, Alta Dirección, 229, 181-185.

MacInTYRe, A. (1987) Tras la virtud. Barcelona, Crítica.

MANen, M. V. (2004) El tono en la enseñanza. El lenguaje de la pedagogía. Barcelona, Paidós.

Marina, J. A. (2004) Aprender a vivir. Barcelona, Ariel.

Markus, H. y Nurius, P. (1986) Possible selves, American Psychologist, 41, 954-969.

Markus, H. y Ruvolo, A. (1989) Possible selves: Personalized representation of goals, en PeRVIN, L. A. (ed.). Goal concepts in personality and social psychology. Hillsdale, NJ, Erlbaum, 211-241.

MASLOW, A. (1962) Toward a psychology of being. Nueva York, Princeton.

(C) Ediciones Universidad de Salamanca

Teor. educ. 17,2005 , pp. 97-128 
McAdams, D. P. (2003) Identity and the life story, en Fivush, R. y Haden, C. A. (eds.). Autobiographical memory and the construction of a narrative self. Developmental and cultural perspectives. Mahwah, NJ Lawrence Erlbaum Associates, 187-207.

MorIN, E. (2001) La mente bien ordenada. Barcelona, Seix Barral.

Morin, E.; Roger, E. y MotTA, R. D. (2003) Educar en la era planetaria. Barcelona, Gedisa.

Ortega y Gasset, J. (1983) Meditaciones del Quijote (Obras Completas, tomo I). Madrid, Alianza y Revista de Occidente.

ORTEGA, P. (2004) Moral education as pedagogy of alterity, Journal of Moral Education, 33 (3), 271-289.

PERVIN, L. A. (1983) The stasis and flow of behavior: Toward a theory of goals, en PAGE, M. M. (ed.). Personality: Current theory and research. Lincoln, University of Nebraska Press, 1-53.

- (ed.) (1989) Goal concepts in personality and social psychology. Hillsdale, NJ, Erlbaum.

PRAT, J. (1986) El emprendedor boy. Barcelona, Hispano Europea.

RicoeUr, P. (1996) Sí mismo como otro. Madrid, Siglo XXI.

Rodríguez Delgado, R. (1997) Del universo al ser humano. Madrid, McGraw-Hill Interamericana.

ROGERS, C. R. (1951) Client-centered therapy. Boston, Houghton Mifflin.

RORTY, R. (1979) Philosophy and the mirror of nature. Princeton, NJ, Princeton University Press.

ROTTER, J. B. (1954) Social learning and clinical psychology. Englewood Cliffs, NJ, Prentice Hall.

RuBIN, D. C. (1986) Superar la indecisión. Barcelona, Grijalbo.

SANFÉLIX, V. (1997) Las identidades del sujeto. Valencia, Pre-Textos.

SARBIN, T. R. (ed.) (1986) Narrative psychology: The storied nature of buman conduct. Nueva York, Praeger.

SaVATER, F. (2004) La libertad como destino. Sevilla, Fundación José Manuel Lara.

SHRAG, C. O. (1997) The self after postmodernity. Nueva York, Yale University Press.

STERNBERG, R. J. (1997) Inteligencia exitosa. Barcelona, Paidós.

TAYLOR, C. (1996) Fuentes del yo. La construcción de la identidad moderna. Barcelona, Paidós.

Tolman, E. C. (1932) Purposive behavior in animals and men. Nueva York, Century.

ToRRaBadella, P. (1997) Cómo desarrollar la inteligencia emocional. Barcelona, Oasis.

VAtTimo, G. (2003) El sujeto y la máscara. Nietzsche y el problema de la liberación. Barcelona, Península.

VÁzQuez, G. (2003) Sociedad-red, ciudadanía cognitiva y educación, Revista de Educación, Núm. Extraordinario, 13-31.

WEBER, M. (1999) La ética protestante y el espiritu del capitalismo (17ª edición). Barcelona, Península.

ZUBIRI, X. (1986) Sobre el hombre. Madrid, Alianza. 